\title{
EFEK KOEFISIEN PERPINDAHAN PANAS KESELURUHAN TERHADAP EFEKTIVITAS SISTEM PENDINGIN BANTALAN GENERATOR
}

\author{
Sri Wuryanti dan Mega Ary Sylvia \\ Jurusan Teknik Konversi Energi-Polteknik Negeri Bandung \\ Email: sriwuryanti.lamda@gmail.com
}

\begin{abstract}
Abstrak
Pada penelitian ini digunakan sistem pendingin jenis heat exchanger (HE) yang berfungsi untuk menurunkan temperatur minyak pelumas, yang digunakan untuk mendinginkan bagian bantalan turbin dan governor. Minyak pelumas yang mengalir melalui selongsong didinginkan oleh air yang mengalir melalui pipa, selanjutnya minyak pelumas tersebut digunakan untuk mendinginkan bearing (bantalan) dan governor. Untuk mendapatkan sistem pendinginan yang optimal, maka perlu dilakukan analisa unjuk kerja dari sistem heat exchanger tersebut yang dalam hal ini adalah nilai efektivitasnya, sehingga dapat diketahui kondisi kelayakan dari sistem heat exchanger tersebut. Salah satu faktor yang mempengaruhi harga efektivitas adalah koefisien perpindahan panas keseluruhan (U). Dari hasil penelitian diperoleh bahwa koefisisen perpindahan panas keseluruhan (U) tertinggi heat exchanger adalah $11,318 \mathrm{~W} / \mathrm{m}^{2}{ }^{\circ} \mathrm{C}$ dan terendah $10,939 \mathrm{~W} / \mathrm{m}^{2}{ }^{\circ} \mathrm{C}$, sehingga efektivitas (c) tertinggi-nya adalah 0,475 dan terendah 0,452. Bila dibandingkan dengan nilai efektivitas standar yaitu 0,5, maka sistem pendinginan tersebut masih mendekati nilai standar sehingga masih layak untuk digunakan.
\end{abstract}

Kata kunci: heat exchanger, sistem pendingin, minyak pelumas, bantalan turbin.

\section{PENDAHULUAN}

Pada sistem pendinginan bantalan generator dengan menggunakan heat exchanger (HE) yang sudah digunakan dalam waktu cukup lama akan mengalami penurunan kinerja yang dalam hal ini adalah penurunan efektivitas sehingga akan berdampak terhadap kemampuan generator tersebut. Salah satu penyebab terjadinya penurunan efektivitas pada sistem pendinginan adalah adanya pengotor yang berasal dari fluida atau cairan yang dapat menghambat terjadinya perpindahan panas, ataupun mungkin sudah terjadi kerusakan pada alat $H E$ tersebut.. Oleh karena itu pada periode waktu tertentu peralatan sistem pendingin tersebut harus selalu dicek dan dibersihkan agar sistem pendinginan dari generator tersebut cukup optimal sehingga generator akan mampu menghasilkan daya yang yang optimal walaupun dibebani cukup besar.

Oleh sebab itu perlu dilakukan analisa kinerja atau efektivitas dari peralatan HE tersebut, apakah terjadinya penurunan efektivitas masih layak atau apakah perlu dilakukan perbaikan bahkan mungkin perlu dilakukan penggantian alat. Hal ini dilakukan karena bantalan (bearing) dan governoor akan mempengaruhi kinerja generator. Salah satu faktor yang mempengaruhi harga efektivitas adalah koefisien perpindahan panas keseluruhan (U).

\section{PERPINDAHAN PANAS}

Alat penukar panas yang digunakan berjenis shell and tube (selongsong dan pipa), dengan dua lintas selongsong dan lebih dari empat lintas pipa. Minyak pelumas dialirkan pada bagian selongsong (pipa luar), sedangkan air pada bagian pipa sebelah dalam. Untuk menghitung harga koefisien perpindahan panas (h) pada bagian pipa luar diberi subscrib "o" dan pada bagian dalam " $i$ ". Jadi koefisien perpindahan panas untuk air yang melalui pipa dalam adalah $h_{i}$ dan untuk minyak pelumas $h_{0}$. Sebelum menghitung $h_{i}$ dan $h_{0}$ terlebih dahulu menghitung bilangan Reynolds untuk menentukan apakah aliran termasuk laminar, transisi atau turbulen. Persamaan untuk menghitung bilangan Reynolds untuk fluida air adalah sebagai berikut:

$$
\mathrm{N}_{\mathrm{Re}}=\frac{\rho x v x d_{i}}{\mu}
$$


dimana,

$$
\begin{aligned}
\mathrm{N}_{\mathrm{Re}} & =\text { bilangan Reynolds, tanpa } \\
& \text { dimensi } \\
\rho & =\text { densitas, } \mathrm{kg} / \mathrm{m}^{2} \\
\mathrm{v} & =\text { kecepatan, } \mathrm{m} / \mathrm{s} \\
& =\mathrm{Q} / \mathrm{A}=\mathrm{Q} /\left(\frac{1}{4} \pi \mathrm{d}_{\mathrm{i}}{ }^{2}\right) \text {, dengan } \mathrm{Q} \\
& \text { adalah laju alir volume air } \\
& =\text { viskositas, } \mathrm{kg} / \mathrm{m} . \mathrm{s} \\
\mu & \text { diameter-pipa, } 0,01587 \mathrm{~m} \\
\mathrm{~d}_{\mathrm{i}} & \text { (dari data teknis) }
\end{aligned}
$$

$\rho, \mu$ diperoleh dari tabel sifat-sifat termodinamik air pada $T_{\text {film }}=T_{\text {rata-rata }}$

Persamaan untuk menghitung bilangan Reynolds untuk fluida pelumas adalah sebagai berikut:

$$
\mathrm{N}_{\mathrm{Re}}=\frac{\rho x v x d_{0}}{\mu}
$$

dimana,

$$
\begin{array}{ll}
\mathrm{N}_{\mathrm{Re}} & =\text { bilangan Reynolds, tanpa } \\
& \text { dimensi } \\
\rho & =\text { densitas, } \mathrm{kg} / \mathrm{m}^{2} \\
\mathrm{v} & =\text { kecepatan, } \mathrm{m} / \mathrm{s} \\
& =\mathrm{Q} / \mathrm{A}=\mathrm{Q} /\left(\frac{1}{4} \pi \mathrm{d}_{\mathrm{o}}{ }^{2}\right), \text { dengan } \mathrm{Q} \\
& \text { adalah laju alir volume } \\
& \text { minyak pelumas } \\
\mu & =\text { viskositas, } \mathrm{kg} / \mathrm{m} . \mathrm{s} \\
\mathrm{d}_{0} & =\text { diameter pipa, } 0,75 \mathrm{~m} \text { (dari } \\
& \text { data teknis) }
\end{array}
$$

p, $\mu$ diperoleh dari tabel sifat-sifat termodinamik minyak pelumas pada $\mathrm{T}_{\text {film }}=$. $T_{\text {rata-rata }}$

Persamaan koefisien perpindahan panas untuk air melalui pipa bagian dalam dengan aliran turbulen adalah sebagai berikut:

dimana,

$$
\mathrm{N}_{\mathrm{Nu}}=0,023 \mathrm{~N}_{\mathrm{Re}}{ }^{0,8} \mathrm{~N}_{\mathrm{Pr}^{0}}{ }^{0,4}
$$

$\mathrm{N}_{\mathrm{Nu}}$ = bilangan Nusselt, tanpa dimensi

$$
=(\mathbf{h x d}) / \mathbf{k}
$$

$\mathrm{N}_{\mathrm{Pr}_{\mathrm{r}}} \quad=$ bilangan Prandtl, tanpa dimensi

$=\left(\mathrm{C}_{\mathrm{p}} \times \mu\right) / \mathrm{k}$

$\mathrm{C}_{\mathrm{p}} \quad=$ kapasitas panas, $\mathrm{kJ} / \mathrm{kg}^{\circ} \mathrm{C}$

$\mathrm{C}_{\mathrm{p}}$ didapat dari tabel pada $\mathrm{T}_{\text {film }}=\mathrm{T}_{\text {rata-rata. }}$ Setelah diperoleh harga $\mathrm{N}_{\mathrm{Nu}}$ dapat dihitung $h_{i}$ karena $\mathrm{N}_{\mathrm{Nu}}=\frac{h_{i} x d_{i}}{k}$, k konduktivitas panas air pada $T_{\text {film }}=T_{\text {rata-rata }}$

Persamaan koefisien perpindahan panas untuk minyak pelumas melalui selosong dengan aliran laminar adalah sebagai berikut:

$\mathrm{N}_{\mathrm{Nu}}=3,66+\frac{0,0668\left(\frac{d_{o}}{L}\right) N_{R e} N_{P r}}{1+0,04\left[\left(\frac{d_{o}}{L}\right) N_{R e} N_{P r}\right]^{2 / 3}}$ dimana,

$\mathrm{L}=$ panjang selongsong $=2,9215 \mathrm{~m}$ (dari data teknis)

Setelah diperoleh harga $\mathrm{N}_{\mathrm{Nu}}$ dapat dihitung $h_{\mathrm{o}}$ karena $\mathrm{N}_{\mathrm{Nu}}=\frac{h_{o} x d_{o}}{k}$

Dari $h_{i}$ dan $h_{o}$, selanjutnya dihitung koefisien perpindahan panas keseluruhan dengan menggunakan persamaan sebagai berikut:

$$
\mathrm{U}_{0}=\frac{1}{\frac{A_{0} 1}{A_{i} h_{i}+\frac{A_{0} \ln \frac{r_{0}}{r_{i}}}{2 \pi k L}+\frac{1}{h_{0}}}}
$$

dimana,

$\mathrm{U}_{\mathrm{o}} \quad=$ koefisien perpindahan panas keseluruhan, $W / m^{2}{ }^{\circ} \mathrm{C}$

$\mathrm{A}_{\mathrm{o}} \quad=$ luas perpindahan panas pipa dalam,

m

$$
\begin{array}{ll} 
& =\pi \times d_{o} \times L \\
A_{i} & = \\
& =\pi \times d_{i} \times L \text { dengan } \mathrm{L}=1,614 \mathrm{~m} \text { (dari } \\
& \quad \text { data teknis) } \\
& =1 / 2 d_{o} \\
r_{0} & =1 / 2 d_{i} \\
r_{i} & \text { konduktivitas panas } \mathrm{Cu}-\mathrm{Ni}=40 \\
k & \text { W/m }{ }^{\circ} \mathrm{C}
\end{array}
$$

Untuk menentukan unjuk kerja atau efektivitas $\mathrm{HE}$, dihitung dengan menggunakan persamaan sebagai berikut:

$\varepsilon=2\left\{1+C+\left(1+C^{2}\right)^{1 / 2} \frac{1+\exp \left[-N\left(1+C^{2}\right)^{1 / 2}\right]}{1-\exp \left[-N\left(1+C^{2}\right)^{1 / 2}\right]}\right\}^{-1}$

(6)

dimana,

$$
\begin{array}{ll}
\mathrm{C}= & \frac{c_{\min }}{c_{\text {maks }}} \text {, dengan } \mathrm{C}_{\min }={\mathrm{m} \times \mathrm{C}_{\mathrm{p}} \text { dan }} \\
& \mathrm{C}_{\text {maks }}=\mathrm{m} \times \mathrm{C}_{\mathrm{p}} \\
\mathrm{N} \quad= & \frac{U \times A}{C_{\min }}
\end{array}
$$

$\mathrm{C}_{\min }$ bisa fluida air atau minyak pelumas dengan cara menghitung $\mathrm{C}_{\mathrm{c}}=\mathrm{m}_{\mathrm{c}} \times \mathrm{C}_{\text {pair }}$ (untuk air) dan $C_{h}=m_{h} \times C_{p}$ minyak (untuk minyak) kemudian dibandingkan mana yang lebih kecil. Begitu juga untuk $\mathrm{C}_{\text {maks }}$.

Perhitungan untuk $m_{c}$ dan $m_{h}$ menggunakan persamaan:

$$
\begin{aligned}
& m_{c}=\left[\left(Q_{\text {air }} \times 10^{-3}\right) / 60\right] \times \rho_{\text {air }} \\
& m_{b}=\left[\left(Q_{\text {minyak }} \times 10^{-3}\right) / 60\right] \times \rho_{\text {minyak }}
\end{aligned}
$$

\section{METODOLOGI}

Pada pelaksanaan penelitian dilakukan tahaptahap sebagai berikut: 
a. Menentukan temperatur air yang masuk dan yang keluar HE;

b. Menentukan temperatur minyak pelumas yang màsuk dan keluar $\mathrm{HE}$;

c. Menentukan laju alir volume air dan minyak pelumas;

d. Menentukan sifat-sifat termodinamik air dan pelumas pada temperatur rata-rata;

e. Melakukan tahap perhitungan dengan menggunakan persamaan (1) sampai (6);

f. Menganalisa hasil perhitungan.

\section{HASIL DAN PEMBAHASAN}

Proses percobaan dilakukan sebanyak 3 kali dan data pengamatan diambil pada kondisi steady setiap dua jam.

Data-data pengamatan ditunjukkan pada Tabel 1, 2 dan 3. Data-data sifat termodinamik air dan minyak pelumas berdasarkan kondisi pada ketiga percobaan ditunjukkan pada Tabel 4, 5 dan 6. Dari data-data sifat termodinamik akan dilakukan perhitungan menggunakan persamaan-persamaan (1) sampai (6) yang hasil perhitungannya ditunjukkan pada Tabel 7, Tabel 8 dan Tabel 9. Sedangkan untuk menghitung kecepatan digunakan persamaan berikut:

a. untuk air:

$\mathrm{Q} /\left(\frac{1}{4} \times \pi \times \mathrm{d}_{\mathrm{i}}^{2} \times 300\right)=$

$\frac{1900 \times 10^{-3} \mathrm{~m}^{3}}{60 s \times \frac{1}{4} \times 3,14 \times 0,01587^{2} \mathrm{~m}^{2} \times 300}=0,534 \mathrm{~m} / \mathrm{s}$

b. untuk minyak pelumas:

$\mathrm{Q} /\left(\frac{1}{4} \mathrm{x} \quad \pi \quad \mathrm{x} \quad \mathrm{d}_{\mathrm{o}}{ }^{2}\right)=\frac{3200 \times 10^{-3} \mathrm{~m}^{3}}{60 \mathrm{~s} \times \frac{1}{4} \times 3,14 \times 0,75^{2} \mathrm{~m}^{2}}=$ $0,121 \mathrm{~m} / \mathrm{s}$

Tabel 1 Data pengamatan pertama

\begin{tabular}{|c|c|c|c|c|c|c|c|c|}
\hline \multirow[t]{2}{*}{ No. Waktu } & \multicolumn{2}{|c|}{ Temperatur a } & \multirow{2}{*}{$\begin{array}{c}\mathrm{T}_{\text {rata-rata }} \\
\left({ }^{\circ} \mathrm{C}\right) \\
\end{array}$} & \multirow{2}{*}{$\begin{array}{c}\mathrm{Q}_{\text {air }} \\
\text { (L/mnt) }\end{array}$} & \multicolumn{2}{|c|}{ Temperatur pelumas } & \multirow{2}{*}{$\begin{array}{c}T_{\text {rata-rata }} \\
\left({ }^{\circ} \mathrm{C}\right)\end{array}$} & \multirow{2}{*}{$\begin{array}{c}Q_{\text {minyak pelumas }} \\
(\mathrm{L} / \mathrm{mnt})\end{array}$} \\
\hline & $\mathrm{T}_{\text {in }}\left({ }^{\circ} \mathrm{C}\right)$ & $\mathrm{T}_{\text {out }}\left({ }^{\circ} \mathrm{C}\right)$ & & & $\mathrm{T}_{\text {in }}\left({ }^{\circ} \mathrm{C}\right)$ & $\mathrm{T}_{\text {out }}\left({ }^{\circ} \mathrm{C}\right)$ & & \\
\hline $\begin{array}{ll}1 & 8: 00\end{array}$ & 24,9 & 27,8 & 26,35 & 1900 & 35,3 & 31,3 & 33,30 & 3200 \\
\hline $210: 00$ & 24,6 & 25,5 & 25,05 & 1900 & 35,0 & 31,1 & 33,05 & 3200 \\
\hline $312: 00$ & 24,9 & 28,0 & 26,45 & 1900 & 35,4 & 31,5 & 33,45 & 3200 \\
\hline $414: 00$ & 25,2 & 28,3 & 26,75 & 1900 & 35,4 & 31,7 & 33,55 & 3200 \\
\hline $5 \quad 16: 00$ & 25,5 & 28,7 & 27,10 & 1900 & 36,0 & 32,2 & 34,10 & 3200 \\
\hline
\end{tabular}

Tabel 2 Data pengamatan kedua

\begin{tabular}{|c|c|c|c|c|c|c|c|c|}
\hline No. Waktu & $\begin{array}{l}\text { Temper } \\
\mathrm{T}_{\text {in }}\left({ }^{\circ} \mathrm{C}\right)\end{array}$ & $\begin{array}{l}\text { ur air } \\
T_{\text {out }}\left({ }^{\circ} \mathrm{C}\right)\end{array}$ & $\begin{array}{c}\mathrm{T}_{\text {rata-rata }} \\
\left({ }^{\circ} \mathrm{C}\right)\end{array}$ & $\begin{array}{c}\mathrm{Q}_{\text {air }} \\
\text { (L/mnt) }\end{array}$ & $\begin{array}{c}\text { Temperat } \\
\mathrm{T}_{\text {in }}\left(^{\circ} \mathrm{C}\right)\end{array}$ & $\begin{array}{l}\text { ir pelumas } \\
\mathrm{T}_{\text {out }}\left({ }^{\circ} \mathrm{C}\right)\end{array}$ & $\begin{array}{c}T_{\text {rata-rata }} \\
\left({ }^{\circ} \mathrm{C}\right)\end{array}$ & $\begin{array}{c}Q_{\text {minyak pelumas }} \\
(\mathrm{L} / \mathrm{mnt})\end{array}$ \\
\hline $\begin{array}{ll}1 & 8: 00\end{array}$ & 25,6 & 28,3 & 26,95 & 1900 & 36,7 & 32,4 & 34,55 & 3200 \\
\hline $210: 00$ & 25,0 & 28,7 & 26,85 & 1900 & 36,5 & 32,0 & 34,25 & 3200 \\
\hline 3 12:00 & 25,1 & 28,0 & 26,55 & 1900 & 37,0 & 32,3 & 34,65 & 3200 \\
\hline $4 \quad 14: 00$ & 24,9 & 28,4 & 26,65 & 1900 & 37,0 & 32,0 & 34,50 & 3200 \\
\hline $\begin{array}{ll}5 & 16: 00\end{array}$ & 25,2 & 28,9 & 27,05 & 1900 & 36,1 & 32,1 & 34,10 & 3200 \\
\hline
\end{tabular}

Tabel 3 Data pengamatan ketiga

\begin{tabular}{|c|c|c|c|c|c|c|c|c|}
\hline No. Waktu & $\begin{array}{l}\text { Temper: } \\
T_{\text {in }}{ }^{\circ} \mathrm{C} \text { ) }\end{array}$ & $\begin{array}{l}\text { tur air } \\
T_{\text {out }}\left({ }^{\circ} \mathrm{C}\right)\end{array}$ & $\begin{array}{c}\mathrm{T}_{\text {rata-rata }} \\
\left({ }^{\circ} \mathrm{C}\right)\end{array}$ & $\begin{array}{c}Q_{\text {air }} \\
\text { (L/mnt) }\end{array}$ & $\begin{array}{l}\text { Temperatur } \\
\mathrm{T}_{\text {in }}\left({ }^{\circ} \mathrm{C}\right)\end{array}$ & $\begin{array}{l}r \text { pelumas } \\
T_{\text {out }}\left({ }^{\circ} \mathrm{C}\right)\end{array}$ & $\begin{array}{c}T_{\text {rata-rata }} \\
\left.\quad{ }^{\circ} \mathrm{C}\right) \\
\end{array}$ & $\begin{array}{l}\mathrm{Q}_{\text {minyal pelumas }} \\
(\mathrm{L} / \mathrm{mnt})\end{array}$ \\
\hline \begin{tabular}{|ll}
1 & $8: 00$ \\
\end{tabular} & 25,4 & 28,4 & 26,90 & 1900 & 35,4 & 31,1 & 33,25 & 3200 \\
\hline $2 \quad 10: 00$ & 25,5 & 28,9 & 27,20 & 1900 & 35,1 & 31,0 & 33,05 & 3200 \\
\hline 3 12:00 & 25,3 & 28,5 & 26,90 & 1900 & 34,8 & 31,5 & 33,15 & 3200 \\
\hline $4 \quad 14: 00$ & 24,9 & 28,3 & 26,60 & 1900 & 34,3 & 31,7 & 33,00 & 3200 \\
\hline $5 \quad 16: 00$ & 24,6 & 28,0 & 26,30 & 1900 & 34,4 & 32,1 & 33,25 & 3200 \\
\hline
\end{tabular}


Tabel 4 Sifat-sifat termodinamik air dan minyak pelumas pada $T_{\text {rata-rata }}$ pengamatan pertama

\begin{tabular}{|c|c|c|c|c|c|c|c|c|c|c|}
\hline \multirow[t]{2}{*}{ No. } & \multicolumn{4}{|c|}{ Air } & \multicolumn{6}{|c|}{ Minyak Pelumas } \\
\hline & $\begin{array}{c}\rho \\
\left(\mathrm{kg} / \mathrm{m}^{3}\right)\end{array}$ & $\underset{\left(\mathrm{kJ} / \mathrm{kg}^{\circ} \mathrm{C}\right)}{\mathrm{C}_{\mathrm{p}^{\circ}}}$ & $\begin{array}{r}\mu \times 10^{-4} \\
(\mathrm{~kg} / \mathrm{m} . \mathrm{s})\end{array}$ & $\begin{array}{c}\mathbf{k} \\
\left(W / m^{\circ} \mathrm{C}\right)\end{array}$ & Pr & $\begin{array}{c}\rho \\
\left(\mathrm{kg} / \mathrm{m}^{3}\right)\end{array}$ & $\begin{array}{c}\mathrm{C}_{\mathrm{p}} \\
\left.\mathrm{kJ} / \mathrm{kg}^{\circ} \mathrm{C}\right)\end{array}$ & $\begin{array}{c}\mu \\
(\mathrm{kg} / \mathrm{m} . \mathrm{s})\end{array}$ & $\begin{array}{c}k \\
\left(W / m^{\circ} \mathrm{C}\right)\end{array}$ & Pr \\
\hline 1 & 995,89 & 4,179 & 8,669 & 0,613 & 5,904 & 880,13 & 1,936 & 0,5299 & 0,144 & 5486,7 \\
\hline 2 & 996,27 & 4,179 & 8,949 & 0,611 & 6,121 & 880,28 & 1,935 & 0,5477 & 0,144 & 5336,1 \\
\hline 3 & 995,86 & 4,179 & 8,647 & 0,613 & 5,887 & 880,04 & 1,936 & 0,5195 & 0,144 & 5298,4 \\
\hline 4 & 995,79 & 4,179 & 8,586 & 0,614 & 5,839 & 879,98 & 1,937 & 0,5127 & 0,144 & 5298,4 \\
\hline 5 & 995,73 & 4,179 & 8,526 & 0,615 & 5,793 & 879,64 & 1,939 & 0,4770 & 0,144 & 5091,4 \\
\hline
\end{tabular}

Tabel 5 Sifat-sifat termodinamik air dan minyak pelumas pada $T_{\text {rata-rata }}$ pengamatan kedua

\begin{tabular}{|c|c|c|c|c|c|c|c|c|c|c|}
\hline \multirow{2}{*}{ No. } & \multicolumn{10}{|c|}{ Minyak Pelumas } \\
\hline & $\begin{array}{c}\rho \\
\left(\mathrm{kg} / \mathrm{m}^{3}\right)\end{array}$ & $\begin{array}{c}\mathrm{C}_{\mathrm{p}} \\
\left(\mathrm{kJ} / \mathrm{kg}^{\circ} \mathrm{C}\right) \\
\end{array}$ & $\begin{array}{c}\mu \times 10^{-4} \\
(\mathrm{~kg} / \mathrm{m} . \mathrm{s})\end{array}$ & $\begin{array}{c}\mathbf{k} \\
\left(\mathrm{W} / \mathrm{m}^{\circ} \mathrm{C}\right) \\
\end{array}$ & $\operatorname{Pr}$ & $\begin{array}{c}\rho \\
\left(\mathrm{kg} / \mathrm{m}^{3}\right)\end{array}$ & $\begin{array}{c}\mathrm{C}_{\mathrm{p}} \\
\left.\mathrm{J} / \mathrm{kg}^{\circ} \mathrm{C}\right)\end{array}$ & $\begin{array}{c}\mu \\
(\mathrm{kg} / \mathrm{m} . \mathrm{s})\end{array}$ & $\begin{array}{c}\mathbf{k} \\
\left(\mathrm{W} / \mathrm{m}^{\circ} \mathrm{C}\right) \\
\end{array}$ & Pr \\
\hline 1 & 995,75 & 4,179 & 8,552 & 0,614 & 5,813 & 879,37 & 1,941 & 0,4498 & 0,144 & 4921,9 \\
\hline 2 & 995,77 & 4,179 & 8,569 & 0,614 & 5,826 & 879,55 & 1,939 & 0,4941 & 0,144 & 5034,9 \\
\hline 3 & 995,83 & 4,179 & 8,626 & 0,618 & 5,871 & 879,31 & 1,942 & 0,4723 & 0,144 & 4884,3 \\
\hline 4 & 995,81 & 4,179 & 8,604 & 0,614 & 5,853 & 879,39 & 1,941 & 0,4821 & 0,144 & 4940,8 \\
\hline 5 & 995,74 & 4,179 & 8,535 & 0,615 & 5,800 & 879,64 & 1,939 & 0,4770 & 0,144 & 5091,4 \\
\hline
\end{tabular}

Tabel 6 Sifat-sifat termodinamik air dan minyak pelumas pada $\mathrm{T}_{\text {rata-rata }}$ pengamatan ketiga

\begin{tabular}{|c|c|c|c|c|c|c|c|c|c|c|}
\hline \multirow{2}{*}{ No. } & \multicolumn{5}{|c|}{ Air } & \multicolumn{5}{|c|}{ Minyak Pelumas } \\
\hline & $\underset{\left(\mathrm{kg} / \mathrm{m}^{3}\right)}{\rho}$ & $\underset{\mathrm{kJ} / \mathrm{kg}^{\circ} \mathrm{C}}{\mathrm{C}_{\mathrm{c}^{\circ}}}$ & $\begin{array}{c}\mu \times 10^{-4} \\
(\mathrm{~kg} / \mathrm{m} . \mathrm{s})\end{array}$ & $\begin{array}{c}\mathbf{k} \\
\left.\mathrm{N} / \mathrm{m}^{\circ} \mathrm{C}\right) \\
\end{array}$ & Pr & $\underset{\left.\mathrm{g} / \mathrm{m}^{3}\right)}{\rho}$ & $\underset{\mathrm{J} / \mathrm{kg}^{\circ} \mathrm{C}}{\mathrm{C}_{\mathrm{O}}}$ & $\begin{array}{c}\mu \\
\mathrm{g} / \mathrm{m} . \mathrm{s})\end{array}$ & $\begin{array}{c}\mathbf{k} \\
\left.\mathrm{V} / \mathrm{m}^{\circ} \mathrm{C}\right)\end{array}$ & $\operatorname{Pr}$ \\
\hline 1 & 995,76 & 4,179 & 8,561 & 0,615 & 5,819 & 880,16 & 1,936 & 0,5334 & 0,144 & 5486,7 \\
\hline 2 & 995,71 & 4,179 & 8,509 & 0,615 & 5,780 & 880,28 & 1,935 & 0,5477 & 0,144 & 5336,1 \\
\hline 3 & 995,76 & 4,179 & 8,561 & 0,614 & 5,819 & 880,22 & 1,935 & 0,5405 & 0,144 & 5298,4 \\
\hline 4 & 995,82 & 4,179 & 8,615 & 0,614 & 5,862 & 880,31 & 1,935 & 0,5514 & 0,144 & 5298,4 \\
\hline 5 & 995,91 & 4,179 & 8,679 & 0,613 & 5,912 & 880,16 & 1,937 & 0,5334 & 0,144 & 5091,4 \\
\hline
\end{tabular}

Tabel 7 Hasil perhitungan pengamatan pertama

\begin{tabular}{|lcccccccccccc|}
\hline No & $\mathrm{N}_{\text {Rei }}$ & $\begin{array}{c}\mathrm{h}_{\mathrm{i}} \\
\left(\mathrm{W} / \mathrm{m}^{20} \mathrm{C}\right)\end{array}$ & $\begin{array}{c}\mathrm{N}_{\text {Reo }} \\
\left(\mathrm{W} / \mathrm{m}^{20} \mathrm{C}\right)\end{array}$ & $\begin{array}{c}\mathrm{h}_{\mathrm{o}} \\
\left(\mathrm{W} / \mathrm{m}^{20} \mathrm{C}\right)\end{array}$ & $\begin{array}{c}\mathrm{m}_{\mathrm{c}} \\
\mathrm{kg} / \mathrm{s})\end{array}$ & $\begin{array}{c}\mathrm{C}_{\mathrm{c}} \\
(\mathrm{kW})\end{array}$ & $\begin{array}{c}\mathrm{m}_{\mathrm{h}} \\
(\mathrm{kg} / \mathrm{s})\end{array}$ & $\begin{array}{c}\mathrm{C}_{\mathrm{h}} \\
(\mathrm{kW})\end{array}$ & $\mathrm{C}$ & $\mathrm{N}$ & $\varepsilon$ \\
\hline 1 & 9733,6 & 2803,3 & 150,46 & 19,66 & 11,257 & 31,54 & 131,8 & 46,65 & 90,3 & 0,685 & 0,858 & 0,474 \\
2 & 9432,0 & 2764,4 & 145,59 & 19,27 & 11,125 & 31,55 & 131,8 & 46,66 & 90,3 & 0,685 & 0,848 & 0,471 \\
3 & 9757,6 & 2820,3 & 133,93 & 18,71 & 10,939 & 31,55 & 131,8 & 46,64 & 90,3 & 0,685 & 0,837 & 0,467 \\
4 & 9826,4 & 2936,2 & 155,48 & 19,63 & 11,257 & 31,53 & 131,8 & 46,64 & 90,3 & 0,685 & 0,857 & 0,473 \\
5 & 9894,9 & 2828,2 & 167,05 & 19,84 & 11,318 & 31,53 & 131,7 & 46,62 & 90,4 & 0,686 & 0,861 & 0,474 \\
\hline
\end{tabular}

Tabel 8 Hasil perhitungan pengamatan kedua

\begin{tabular}{|lcccccccccccc|}
\hline No & $\mathrm{N}_{\text {Rei }}$ & $\begin{array}{c}\mathrm{h}_{\mathrm{i}} \\
\left(\mathrm{W} / \mathrm{m}^{20} \mathrm{C}\right)\end{array}$ & $\mathrm{N}_{\text {Reo }}$ & $\begin{array}{c}\mathrm{h}_{\mathrm{o}} \\
\left(\mathrm{W} / \mathrm{m}^{20} \mathrm{C}\right)\end{array}$ & $\begin{array}{c}\mathrm{U}_{\mathrm{o}} \\
\left(\mathrm{W} / \mathrm{m}^{20} \mathrm{C}\right)\end{array}$ & $\left.\begin{array}{c}\mathrm{m}_{\mathrm{c}} \\
(\mathrm{kg} / \mathrm{s})\end{array}\right) \begin{array}{c}\mathrm{C}_{\mathrm{c}} \\
(\mathrm{kW})\end{array}$ & $\begin{array}{c}\mathrm{m}_{\mathrm{h}} \\
(\mathrm{kg} / \mathrm{s})\end{array}$ & $\begin{array}{c}\mathrm{C}_{\mathrm{h}} \\
(\mathrm{kW})\end{array}$ & $\mathrm{C}$ & $\mathrm{N}$ & $\varepsilon$ \\
\hline 1 & 9865,4 & 2820,8 & 177,09 & 19,99 & 11,366 & 31,53 & 131,8 & 46,61 & 90,47 & 0,686 & 0,864 & 0,475 \\
2 & 9845,9 & 2818,8 & 161,25 & 19,68 & 11,179 & 31,53 & 131,7 & 46,62 & 90,43 & 0,686 & 0,849 & 0,464 \\
3 & 9781,8 & 2931,7 & 168,65 & 19,63 & 11,257 & 31,53 & 131,8 & 46,60 & 90,48 & 0,687 & 0,856 & 0,473 \\
4 & 9806,0 & 2814,9 & 165,23 & 19,56 & 11,225 & 31,53 & 131,8 & 46,61 & 90,46 & 0,686 & 0,854 & 0,472 \\
5 & 9885,1 & 2815,8 & 167,05 & 19,84 & 11,317 & 31,53 & 131,8 & 46,62 & 90,41 & 0,686 & 0,865 & 0,475 \\
\hline
\end{tabular}


Tabel 9 Hasil perhitungan pengamatan ketiga

\begin{tabular}{|lcccccccccccc|}
\hline No & $\mathrm{N}_{\text {Rei }}$ & $\begin{array}{c}\mathrm{h}_{\mathrm{i}} \\
\left(\mathrm{W} / \mathrm{m}^{20} \mathrm{C}\right)\end{array}$ & $\mathrm{N}_{\text {Reo }}$ & $\begin{array}{c}\mathrm{h}_{\mathrm{o}} \\
\left(\mathrm{W} / \mathrm{m}^{20} \mathrm{C}\right)\end{array}$ & $\begin{array}{c}\mathrm{U}_{\mathrm{o}} \\
\left(\mathrm{W} / \mathrm{m}^{20} \mathrm{C}\right)\end{array}$ & $\begin{array}{c}\mathrm{m}_{\mathrm{c}} \\
(\mathrm{kg} / \mathrm{s})\end{array}$ & $\begin{array}{c}\mathrm{C}_{\mathrm{c}}(\mathrm{kW}) \\
(\mathrm{m})\end{array}$ & $\left.\begin{array}{c}\mathrm{m}_{\mathrm{h}} \\
(\mathrm{kg} / \mathrm{s})\end{array}\right) \begin{array}{c}\mathrm{C}_{\mathrm{h}} \\
(\mathrm{kW})\end{array}$ & $\mathrm{C}$ & $\mathrm{N}$ & $\varepsilon$ \\
\hline 1 & 9855,6 & 2819,7 & 148,47 & 19,57 & 11,229 & 31,53 & 131,8 & 46,65 & 90,29 & 0,685 & 0,856 & 0,454 \\
2 & 9914,6 & 2830,1 & 145,53 & 19,27 & 11,131 & 31,53 & 131,8 & 46,65 & 90,27 & 0,685 & 0,848 & 0,452 \\
3 & 9855,6 & 2939,1 & 147,52 & 19,31 & 11,152 & 31,53 & 131,8 & 46,65 & 90,28 & 0,685 & 0,849 & 0,471 \\
4 & 9793,9 & 2813,9 & 144,62 & 19,18 & 11,099 & 31,53 & 131,8 & 46,66 & 90,26 & 0,685 & 0,846 & 0,470 \\
5 & 9721,7 & 2802,5 & 149,47 & 19,14 & 11,085 & 31,54 & 131,8 & 46,65 & 90,29 & 0,685 & 0,845 & 0,470 \\
\hline
\end{tabular}

Dari tabel hasil perhitungan (Tabel 7,8 dan 9) terlihat bahwa harga koefisien perpindahan panas keseluruhan yang semakin besar akan memberikan efek nilai efektivitas sistem pendingin heat exchanger (HE) yang makin besar pula, demikian pula sebaliknya. Hal ini terlihat pada data dengan $U_{0}$ tertinggi $(11,366$ $\mathrm{W} / \mathrm{m}^{20} \mathrm{C}$ ) memberikan nilai efektivitas tertinggi $(0,475)$, sedangkan pada $U_{0}$ terendah $\left(10,939 \mathrm{~W} / \mathrm{m}^{20} \mathrm{C}\right)$ memberikan nilai efektivitas yang rendah $(0,467)$. Akan tetapi koefisien perpindahan panas ini hanyalah merupakan salah satu faktor yang mempengaruhi nilai efektivitas, karena masih ada faktor-faktor lain yaitu harga perbedaan temperatur masuk dan keluar yang akan mempengaruhi harga kapasitas panas, juga dapat mempengaruhi harga $C_{c}$ dan $C_{h}$. Dari harga $C c$ dan $C_{h}$ akan mempengaruhi harga $C$, hal ini terlihat pada persamaan efektifitas yang dipengaruhi oleh harga $\mathrm{N}$ dan $\mathrm{C}$. Sehingga hubungan data Uo dan efektivitas pada tabel-tabel di atas kadang terjadi penyimpangan.

Bila dibandingkan dengan nilai efektivitas standar yaitu 0,5, maka nilai efektivitas heat exchanger pada penelitian ini (berkisar antara $0,452$ sampai 0,476$)$ masih mendekati angka standar; dengan demikian alat heat exchanger tersebut masih layak untuk digunakan.

\section{KESIMPULAN}

Harga koefisien perpindahan panas keseluruhan yang semakin besar akan memberikan efek nilai efektivitas sistem pendingin heat exchanger (HE) yang makin besar pula, demikian pula sebaliknya.

Bila dibandingkan dengan nilai efektivitas standar yaitu 0,5 , maka nilai efektivitas system pendingin heat exchanger pada penelitian ini masih mendekati standar, sehingga alat tersebut masih layak untuk digunakan.

\section{DAFTAR PUSTAKA}

http://www.cooper.org/applications/cuni/app des.html: Konduktivitas Thermal Bahan Coil (Cu-Ni), 2008

http://www.enerfin-inc.com.: Oil Cooler, 2008 http://www.nsrp.org/documents/flux cored_el ectrode.pdf.: Physical and Mechanical Properties of Wrought Cu-Ni, 2008

http://www.taftan.com/thermodynamics: Heat Exchanger Shell and Tube, 2008

Rolle, Kurt C.,"Heat and Mass Transfer", New Jersey: Prentice-Hall. Inc., 2000 , "Trust Lubricants Handbook", Jakarta: PT Indoteras Nusantara, 2002 